IZA DP No. 6569

Subjective Well-Being and Relative Poverty in Rural Bangladesh

Mohammad Niaz Asadullah Nazmul Chaudhury

May 2012 


\title{
Subjective Well-Being and Relative Poverty in Rural Bangladesh
}

\author{
Mohammad Niaz Asadullah \\ University of Reading, \\ ESRC and IZA \\ Nazmul Chaudhury \\ RED, BRAC \\ and World Bank
}
Discussion Paper No. 6569
May 2012

\author{
IZA \\ P.O. Box 7240 \\ 53072 Bonn \\ Germany \\ Phone: +49-228-3894-0 \\ Fax: +49-228-3894-180 \\ E-mail: iza@iza.org
}

\begin{abstract}
Any opinions expressed here are those of the author(s) and not those of IZA. Research published in this series may include views on policy, but the institute itself takes no institutional policy positions.

The Institute for the Study of Labor (IZA) in Bonn is a local and virtual international research center and a place of communication between science, politics and business. IZA is an independent nonprofit organization supported by Deutsche Post Foundation. The center is associated with the University of Bonn and offers a stimulating research environment through its international network, workshops and conferences, data service, project support, research visits and doctoral program. IZA engages in (i) original and internationally competitive research in all fields of labor economics, (ii) development of policy concepts, and (iii) dissemination of research results and concepts to the interested public.
\end{abstract}

IZA Discussion Papers often represent preliminary work and are circulated to encourage discussion. Citation of such a paper should account for its provisional character. A revised version may be available directly from the author. 


\section{ABSTRACT \\ Subjective Well-Being and Relative Poverty in Rural Bangladesh ${ }^{*}$}

This paper revisits the debate over the importance of absolute vs. relative income as a correlate of subjective well-being using data from Bangladesh, one of the poorest countries in the world with high levels of corruption and poor governance. We do so by combining household data with population census and village survey records. Our results show that conditional on own household income, respondents report higher satisfaction levels when they experience an increase in their income over the past years. More importantly, individuals who report their income to be lower than their neighbours in the village also report less satisfaction with life. At the same time, our evidence suggests that relative wealth effect is stronger for the rich. Similarly, in villages with higher inequality, individuals report less satisfaction with life. However, when compared to the effect of absolute income, these effects (i.e. relative income and local inequality) are modest. Amongst other factors, we study the influence of institutional quality. Institutional quality, measured in terms of confidence in police, matters for well-being: it enters with a positive and significant coefficient in the wellbeing function.

JEL Classification: $\quad 012,130,131$

Keywords: poverty, well-being, institutions, Bangladesh

Corresponding author:

M Niaz Asadullah

Department of Economics

University of Reading

PO Box 218, Whiteknights

Reading RG6 6AA

United Kingdom

E-mail:m.asadullah@reading.ac.uk

\footnotetext{
* Niaz Asadullah gratefully acknowledges support from the Leverhulme Trust UK and Research and Evaluation Division (RED) of Bangladesh Rural Advancement Committee (BRAC). We express our appreciation for additional funding and institutional support from the South Asia Human Development, World Bank as well as the Bangladesh Country Management Unit. This study does not necessarily reflect the views of the World Bank or the Governments they represent. Lastly, we would like to thank Zihad Hassan who managed survey work with utmost professional competence. An earlier version of the paper was presented at a seminar in the Institute of Microfinance (InM), Dhaka. We are grateful to seminar participants and Shahid Khandker for helpful comments.
} 


\section{Introduction}

Of late, there has been a spate of economic investigations on the determinants of subjective life-satisfaction. Arguing that life-satisfaction scores provide a measure of true utility ${ }^{1}$, findings of these studies have been used to highlight both economic and non-economic aspects of individual well-being. Evidence suggests that relative to income, influence of other factors is either of equal or even greater importance. This is a promising line of inquiry in the context of the existing debate on the multidimensionality of poverty. Life-satisfaction research, by way of jointly studying the role of institutions, belief system, income and, economic inequality and so on, provides a convenient way to compare and contrast economic and non-economic factors in determining individual well-being. If well-being cannot be defined in the commodity space, the influence of income vis-à-vis that of non-income variables should be modest. To this end, research using developed country data finds that nonincome related factors matter as well. Well-being is lower in countries where inflation is high, institutions are of poor quality (Helliwell, 2003; Helliwell, 2006) and, inequality is high (Alesina, Di Tella and MacCulloch, 2004²). Cross-country analysis on the correlates of well-being reveals that even after holding income constant, difference in happiness is explained by unemployment level in the economy (Clark and Oswald, 1994) and level of trust in the society (Helliwell and Putnam, 2004; Helliwell and Huang, 2005; Helliwell and Wang, 2010).

Using four rounds of World Values Survey data spanning 75 countries, Helliwell (2003) finds that income effect is dominated by government quality. Another notable aspect of this study is the finding that for different stages of development, different type of government institutions is relevant. Honest governments are more important in low income countries whilst political stability is more relevant for developed

\footnotetext{
1 There is a wide-acceptance of the use of subjective data today. Although economists have traditionally focused on revealed preferences, analysis of self-reported wellbeing measures reveals that (a) well-being equations are broadly "similar" across countries suggesting that the data does not just contain noise; (b) answers to life satisfaction questions are clearly correlated with a number of observable phenomena that are true indicators of wellbeing such as the risk of coronary heart disease, hypertension, stress, depression, anxiety, pain, blood-pressure measures (Oswald, 1997; Blanchflower and Oswald, 2008); (c) suicide rate (which is based on behaviour rather than subjective opinions and arguably a true measure of utility) also predicts life-satisfaction (Helliwell, 2004). This suggests that even if happiness scores measure true internal utility with some noise, the signal-to-noise ratio is sufficiently high to make empirical research productive (Di Tella and MacCulloch, 2006).

${ }^{2}$ Alesina et al. find that wage inequality depresses reported happiness in a region in both US and Europe.
} 
countries. Second, the effect of institutional quality is found to dominate that of GDP. Lastly, well-being gains from better institutions are larger amongst the poor (because they suffer most from corruption).

In parallel to the cross-country studies, there exists a large body of literature which employs country-specific micro datasets. This research finds sizable reference group effects. For the US, it is found that relative income not only affects well-being positively, change in welfare owing to increase in mean income in residential locality is equal to fall in personal income using US data (Luttmer, 2004). Similarly, Helliwell and Huang (2009) find that family/personal income and mean income in census tract equally affect in Canada ${ }^{3}$. Similarly, using Danish data Clark, Kristensen and Westergård-Nielsen (2009) find that conditional on own household income, respondents report higher satisfaction levels when their neighbours are richer. The finding that relative instead of absolute income has a stronger effect as a correlate of well-being has important policy implication: if the poor cares about their relative position in the income distribution, policies that aim to raise their welfare has to additionally address the issue of economic inequality.

This paper builds on the existing developed country studies and contributes to the small but growing developing country literature on subjective well-being using a new household survey dataset from rural Bangladesh that spans 96 villages. In particular, we follow Halliwell (2003) and combine individual and aggregate (i.e. community) level variables to explain well-being. Respondents in our survey were asked, among other things, the following question (which they answered on a scale of 1-10): “On the whole, how satisfied are you with your life?" We use this subjective assessment of life-satisfaction or happiness ${ }^{4}$ as a proxy measure of "utility", and estimate well-being

\footnotetext{
${ }^{3}$ Similar reference group effect is also reported for other correlate of welfare: Clark (2003) finds that an unemployed person's wellbeing is positively correlated with regional/household unemployment.

${ }^{4}$ We treat the terms "life satisfaction" and happiness interchangeably.

${ }^{5}$ The measurement of subjective well-being confounds interpersonal comparisons of welfare using subjective data (Kahneman and Krueger, 2006). For instance, a methodological problem is that life satisfaction score assumes cardinality whilst satisfaction scores are not necessarily homogenous across individuals. Whilst recent evidence confirms the latter point, at the same time it is pointed out that this issue does not cause bias in the analysis of self-reported well-being data. Beegle et al. (2009) use vignettes to test for heterogeneity in satisfaction score scales and evaluate its effect on happiness scores for Tajikistan. Beegle et al. confirm the presence of individual-specific scales or standards when assessing well-being. But the authors find little bias in the identification of correlates of life satisfaction when vignette responses are included as control variables in standard well-being regressions.
} 
function focusing on a number of correlates: relative wealth, institutional quality, and social trust. The key hypotheses tested are: (a) Is the effect of absolute income bigger than relative income? (b) Is the relative income effect only specific to the non-poor? (c) How does the income effect compare with that of institutional quality, social trust and economic inequality in the village?

Rest of the paper is organized as follows. Section 2 discusses studies on subjective well-being using developing country data. Section 3 discusses the data and the main hypotheses. Section 4 discusses the methodology. Section 5 presents the main results. Section 6 is conclusion.

\section{Literature review: Subjective well-being in low income countries}

Inspired by the evidence for developed countries, researchers have started to estimate well-being equations using developing country data. Using Malawian data, Ravallion and Lokshin (2010) report that subjective well-being is negatively correlated with mean income in one's neighbourhood but this is true only for the non-poor (i.e. individuals in the upper income category). Needs in developing societies are somewhat basic in nature so that a priori, income deprivation seems to be the correct yardstick to focus on from policy point of view. However, more recent research using Nepalese data contradicts Ravallion and Lokshin. For instance, Fafchamps and Shilpi (2009) find that relative consumption is an important predictor of subjective welfare even in mountainous villages of Nepal where households remain isolated from the influence of modernity ${ }^{6}$. In another related study on South Africa, Kingdon and Knight (2007) also report some evidence of relative income effect: subjective wellbeing is found to increase with average income in the district ${ }^{7}$. On the other hand, descriptive evidence of reference group consumption effect reported by Guillen-Royo (2011) for Peru suggests that neighbours are 'negatives'. Similarly, using Indian data Carlsson, Gupta and Johansson-Stenman (2009) find that majority of the marginal utility of income comes from some kind of relative income effects. Individuals with

\footnotetext{
${ }^{6}$ Therefore, for these villages, the correlation between relative consumption and subjective wellbeing cannot be attributed to the possibility that relative comparisons are exacerbated by urban influence and exposure to market activities.

${ }^{7}$ Kingdon and Knight find that close neighbors are 'positives' but that the income of more distant others negatively enters the well-being function. They also find that income of racially defined reference groups have a negative effect.
} 
low family income have higher concern for relative income. More interestingly, an increase in the average income of the caste to which the individual belongs reduces utility for the individual. Other studies on the determinants of subjective well-being also include Knight, Song and Gunatilaka (2009) and Knight and Gunatilaka (2010) for China and Fafchamps and Kebede (2008) for Ethiopia. All the three studies confirm the importance of relative income.

For reasons related to data unavailability, research on subjective well-being in low income countries still remains limited. Apart from the studies cited above, we are not aware of other published developing country research on this question ${ }^{8}$. More importantly, we know nothing about the role of institutional quality, social trust in the community and religious belief of an individual -- none of the published developing country studies cited in this section focuses on these other non-income related factors.

For a number of reasons, well-being research on Bangladesh is important from the broader literature point of view. First, Bangladeshis are said to have higher level of happiness despite extreme poverty (Worcester, 1998). If true, other non-income and social factors may be at play for individual well-being even in a society where basic needs to lead a minimally physically secure life is rarely met.

Second, Bangladesh is well-known for various forms of governance crisis (Mahmud, Ahmed and Mahajan, 2008). Documented cases of corruption are not only specific to the public sector, corruption is also rampant in social sectors ${ }^{9}$. Corruption in public service delivery in the form of absenteeism of health and education service providers is a serious problem in rural Bangladesh (Chaudhury and Hammer, 2003; Chaudhury et al., 2006). Households in Bangladesh also report paying bribes to the police. Such poor quality of social and legal institutions can be expected to undermine well-being in rural societies. Moreover, the poor quality of public institutions in the country has

\footnotetext{
${ }^{8} \mathrm{We}$ are aware of a number of additional studies on well-being research. McGregor, McKay and Velazco (2007) focus on subjective well-being using Bangladeshi data. However, this study is highly descriptive and do not report any estimate of the well-being function. Kohler, Peter, Behrman and Skytthe (2005) on the other hand estimate well-being functional for Philippines but focuses on the fertility as a correlate of life-satisfaction.

9 The World Bank report Voices of the Poor highlights additional sources of poverty amongst individuals who are normally considered to be poor only in terms of market-based measures of deprivation. Indeed corruption emerges as a core issue of poverty in Bangladesh in the report (Nabi, Datta, Chakrabarty, Begum and Chaudhury, 1999).
} 
led to poor ranking in the global survey on corruption perceptions. In such a high corruption country, trust is likely to be low and this in turn can lower well-being ${ }^{10}$.

Third, in recent years, there has been a reported fall in life satisfaction score despite a significant fall in poverty rate in Bangladesh: happiness score declined from 85\% (in 1995) to $60 \%$ (in 2000) vs. fall in Human Poverty Index (HPI) from 61\% (in 1983) to $36 \%$ (in 2000) (Sen and Hulme, 2004). This then questions the role of absolute income as the sole determinant of well-being. There is a parallel for this trend in the broader literature, namely the global happiness puzzle, where it is argued that income growth does not lead to gains in well-being (Easterlin, 1974). Given the evidence of sustained spell of economic growth without any increase in individual happiness, many ask whether the current income is relevant component in the well-being function.

What explains the Bangladeshi puzzle of declining life satisfaction in an era of economic growth and poverty reduction is not known as there is no micro dataset that provides repeated info on life satisfaction scores. It is neither our objective to answer this puzzle. Rather, we use cross-section data to provide the first set of estimates of a well-being function for Bangladesh ${ }^{11}$ with a focus on institutional quality and relative income.

\section{Data}

Data used in this paper comes from a multi-purpose household survey fielded by the World Bank in 2008 in rural Bangladesh. The survey was designed by the authors. We randomly selected 12 districts from 6 divisions (highest administrative unit in Bangladesh). The probability proportional to size (PPS) method of random sampling was used, based on division/district level secondary school going age population data from the 2001 national population census and the concentration of secondary schools and Madrassahs based on BANBEIS website 2007. Two upazilas (sub-districts) were

\footnotetext{
${ }^{10}$ Indeed, cross-country studies show that trust in police is strongly correlated with quality of government services (e.g. see Helliwell and Huang, 2008).

${ }^{11}$ We are only aware of one descriptive study -- Camfield, Choudhury and Devine (2009) --on wellbeing in Bangladesh. However, the study sample used is very limited in terms of geographical coverage. Neither is it nationally representative nor rich enough to undertake quantitative analysis of determinants of well-being.
} 
randomly selected using PPS from each of the selected 12 districts. Then 2 unions were randomly selected with PPS from each of the selected 24 upazilas. Again, the population weight was union level population data from the 2001 national population census.

For each of the 48 sample Unions, we randomly selected 2 villages using with "probability proportional to size" (PPS) based on village-level population data from the 2001 national census. A complete census of all households was carried out in each sample village. From the census household frame, 25 households were randomly selected from each village. Then, detailed multi-module household survey was administered (e.g., complete roster, education history, employment status, assets, consumption and so on). This led to detailed data on 2,400 households.

Table 1 presents the summary statistics. This is based on a total of 2318 adults for whom life-satisfaction score is reported and other household and individual-specific information are non-missing. Table 1 also reports the summary statistics by income groups. Individuals in the bottom $40 \%$ income have very low level of human capital only $2 \%$ of them have secondary education or above compared to $15 \%$ of the individuals whose income is in the top $60 \%$. Poorer individuals are also less satisfied when they compare their current wealth with that of the past and others in the village. Mean values of these two variables, on the other hand, are higher for individuals in the top $60 \%$ income. Poorer individuals also have lower institutional and social trust compared to better-off households. Lastly, they live in villages that are less-developed when compared to better-off individuals as indicated by the value of the "village development index" variable. 
Table 1: Descriptive statistics and variable definitions

\begin{tabular}{|c|c|c|c|c|c|c|}
\hline \multirow[t]{2}{*}{ Variable } & Mean & Std. Dev. & Mean & Std. Dev. & \multirow{2}{*}{\multicolumn{2}{|c|}{$\begin{array}{c}\text { Top } 60 \% \text { income } \\
\text { group }\end{array}$}} \\
\hline & \multicolumn{2}{|c|}{ Full sample } & \multicolumn{2}{|c|}{$\begin{array}{c}\text { Bottom } 40 \% \text { income } \\
\text { group }\end{array}$} & & \\
\hline Female & 0.66 & 0.47 & 0.66 & 0.47 & 0.66 & 0.47 \\
\hline Muslim & 0.92 & 0.27 & 0.94 & 0.24 & 0.91 & 0.29 \\
\hline Age & 40.40 & 10.51 & 40.20 & 9.98 & 40.52 & 10.83 \\
\hline age_2 & 17.42 & 9.12 & 17.16 & 8.51 & 17.59 & 9.48 \\
\hline Married & 0.90 & 0.31 & 0.91 & 0.29 & 0.89 & 0.32 \\
\hline Education: primary completed & 0.16 & 0.37 & 0.11 & 0.32 & 0.19 & 0.39 \\
\hline Education: some secondary education & 0.17 & 0.37 & 0.09 & 0.28 & 0.22 & 0.41 \\
\hline Education: secondary education or above & 0.06 & 0.24 & 0.02 & 0.15 & 0.09 & 0.29 \\
\hline Log of per capita hh expenditure & 7.55 & 0.45 & 7.11 & 0.23 & 7.82 & 0.31 \\
\hline Landless household & 0.58 & 0.49 & 0.54 & 0.50 & 0.60 & 0.49 \\
\hline No adverse shock in the last 1 year & 0.39 & 0.49 & 0.40 & 0.49 & 0.38 & 0.48 \\
\hline \# of days being sick & 1.86 & 4.86 & 1.48 & 4.09 & 2.11 & 5.27 \\
\hline Wealth relative to 5 years ago ( $1=$ lot less ; $5=$ lot higher $)$ & 2.99 & 1.06 & 2.68 & 1.05 & 3.18 & 1.01 \\
\hline Wealth w.r.to others in village ( $1=$ lot less; $5=$ lot higher) & 2.56 & 1.05 & 2.18 & 0.94 & 2.80 & 1.05 \\
\hline Institutional trust: Confidence in police ( $1=$ low; $5=$ high $)$ & 3.56 & 1.13 & 3.53 & 1.11 & 3.58 & 1.14 \\
\hline Educational inequality amongst villagers & 3.70 & 0.46 & 3.62 & 0.52 & 3.76 & 0.41 \\
\hline Land inequality amongst villagers & 115.97 & 50.49 & 116.39 & 48.93 & 115.72 & 51.46 \\
\hline Social trust in the village ( $1=$ can't be trusted; $4=$ can be fully trusted $)$ & 3.45 & 0.71 & 3.39 & 0.75 & 3.49 & 0.67 \\
\hline Village development index & 2.20 & 1.35 & 2.06 & 1.33 & 2.29 & 1.35 \\
\hline $\mathrm{N}$ & 2318 & & 895 & & 1423 & \\
\hline
\end{tabular}

Note: (a) per capita expenditure is computed following the methodology outlined in Ahmed and Shams (1994). To be precise, we used the information on age, weight, and sex, from rural Bangladesh to compute calorie requirements, which assume a moderate level of physical activity. On this basis, adult-equivalent per capita consumption figures were computed. (b) The variable "Village development index" is a sum of the following 7 facilities being available in the village: police station, post office, health care centre, pucca road, telephone line, electricity and satellite dish.

Life satisfaction for each respondent is measured on a scale of 1 to 10 . The complete distribution of responses to life satisfaction question is shown in Table 2. The proportion of respondents opting for the highest five of ten possible levels of subjective well-being is $46.81 \%$ and the proportion reporting the lowest two only $9 \%$. However, there is considerable variation across the quintiles of income per capita: whereas $36 \%$ in the lowest quintile report happiness in the range of 6-10 points, the figure for the highest quintile is $67 \%$. When the categories of satisfaction are converted into cardinal values (ranging from a score of 10 for "very satisfied" down to 0 for not satisfied at all), the mean score (5.63 for the sample as a whole) rises monotonically from 4.44 in the lowest to 6.62 in the highest quintile. Therefore, whilst there is a positive correlation between income and life satisfaction, there is much more to subjective well-being than what is explained by absolute household income. 
Table 2: Percentage of respondents by level of life satisfaction, overall and by income quintile

\begin{tabular}{lcccccc}
\hline & & \multicolumn{5}{c}{ Income quintile } \\
\cline { 3 - 7 } & Overall & 1 & 2 & 3 & 4 & 5 \\
\hline 1 & 3.15 & 7.18 & 2.81 & 2.53 & 1.94 & 1.65 \\
2 & 5.69 & 12.27 & 7.56 & 3.59 & 3.02 & 2.67 \\
3 & 9.88 & 16.67 & 15.12 & 9.7 & 6.48 & 2.26 \\
4 & 13.5 & 19.68 & 18.14 & 12.03 & 12.31 & 6.17 \\
5 & 20.97 & 18.06 & 20.3 & 25.53 & 20.52 & 20.16 \\
6 & 12.73 & 10.65 & 11.45 & 11.81 & 14.69 & 14.81 \\
7 & 10.96 & 4.17 & 8.86 & 12.45 & 12.53 & 16.05 \\
8 & 9.84 & 6.25 & 5.62 & 9.07 & 11.23 & 16.46 \\
9 & 4.44 & 0.93 & 2.16 & 2.74 & 8.64 & 7.41 \\
10 & 8.84 & 4.17 & 7.99 & 10.55 & 8.64 & 12.35 \\
$\mathrm{~N}$ & 2,318 & 432 & 463 & 474 & 463 & 486 \\
Mean LS & 5.63 & 4.44 & 5.12 & 5.75 & 6.09 & 6.62 \\
\hline Note: Data for this table and for all subsequent tables are derived from the QSSMEB survey.
\end{tabular}

Respondents in our survey were asked to compare their current living standard with that five years ago in terms of household wealth. Table 3 cross-tabulates this data with life satisfaction score. First thing to note is that $42 \%$ of them now had at least somewhat higher living standard whilst $36 \%$ had become at least somewhat worse off. It also shows that, among those currently highly better off, $66.66 \%$ reported satisfaction in the range of 6-10 points, among those at the same level the corresponding figure was $49 \%$, and among those very worse off it was $20.72 \%$. The mean happiness scores were 4.24, 5.69, and 6.92 respectively. It is clear that the feeling of relative deprivation by comparison with their past does affect the satisfaction of respondents in our data. 
Table 3: The percentage of respondents by level of life satisfaction and by relative living standard

\begin{tabular}{|c|c|c|c|c|c|c|}
\hline & \multirow[b]{2}{*}{ Overall } & \multicolumn{5}{|c|}{ Current living standard (relative to the past) } \\
\hline & & $\begin{array}{c}\text { Much } \\
\text { worse } \\
\text { off } \\
\text { than } \\
\text { before }\end{array}$ & $\begin{array}{r}\text { Somewhat } \\
\text { worse off } \\
\text { than } \\
\text { before }\end{array}$ & $\begin{array}{r}\text { Same } \\
\text { as } \\
\text { before }\end{array}$ & $\begin{array}{r}\text { Somewhat } \\
\text { richer } \\
\text { than } \\
\text { before }\end{array}$ & $\begin{array}{r}\text { Much } \\
\text { richer } \\
\text { than } \\
\text { before }\end{array}$ \\
\hline 1 & 3.15 & 11.26 & 2.75 & 3.78 & 1.15 & 0 \\
\hline 2 & 5.69 & 13.51 & 9.45 & 4.12 & 2.65 & 0 \\
\hline 3 & 9.88 & 15.77 & 11.86 & 9.62 & 7.83 & 1.59 \\
\hline 4 & 13.5 & 19.82 & 15.46 & 12.03 & 11.85 & 9.52 \\
\hline 5 & 20.97 & 18.92 & 20.79 & 21.31 & 21.29 & 22.22 \\
\hline 6 & 12.73 & 6.31 & 10.14 & 14.95 & 14.84 & 9.52 \\
\hline 7 & 10.96 & 2.7 & 8.76 & 11.68 & 13.46 & 19.05 \\
\hline 8 & 9.84 & 4.5 & 10.14 & 9.79 & 10.93 & 11.11 \\
\hline 9 & 4.44 & 0.45 & 2.75 & 3.78 & 6.56 & 11.11 \\
\hline 10 & 8.84 & 6.76 & 7.9 & 8.93 & 9.44 & 15.87 \\
\hline $\mathrm{N}$ & 2318 & 222 & 582 & 582 & 869 & 63 \\
\hline Mean LS & 5.63 & 4.24 & 5.30 & 5.69 & 6.08 & 6.92 \\
\hline
\end{tabular}

Note: (a) Relative living standard is defined on the basis of comparison of current wealth with that five years ago. (b) The total number of observations is 2319 . The mean happiness score relates only to those who reported a happiness level.

We also asked respondents about their perceived relative economic status within the household. To be precise, respondent answers were classified according to their responses to the question: "Is your current living standard much below average, below average, average, above average, or much above average for your village?" Table 4 shows a skewed distribution around the average status with the majority $51 \%$ regarding their living standard as being below average and only $22 \%$ above. The proportion reporting satisfaction in the range of 6-10 points rises monotonically with relative living standard, from $36 \%$ in the lowest category to $67 \%$ in the highest. The mean happiness score also rises monotonically, from 4.78 to 7.32 . It is evident that the feeling of relative deprivation by comparison with others in their village affects wellbeing of respondents in our sample. 
Table 4: The percentage of respondents by level of life satisfaction and by comparison of current wealth with that of other villagers

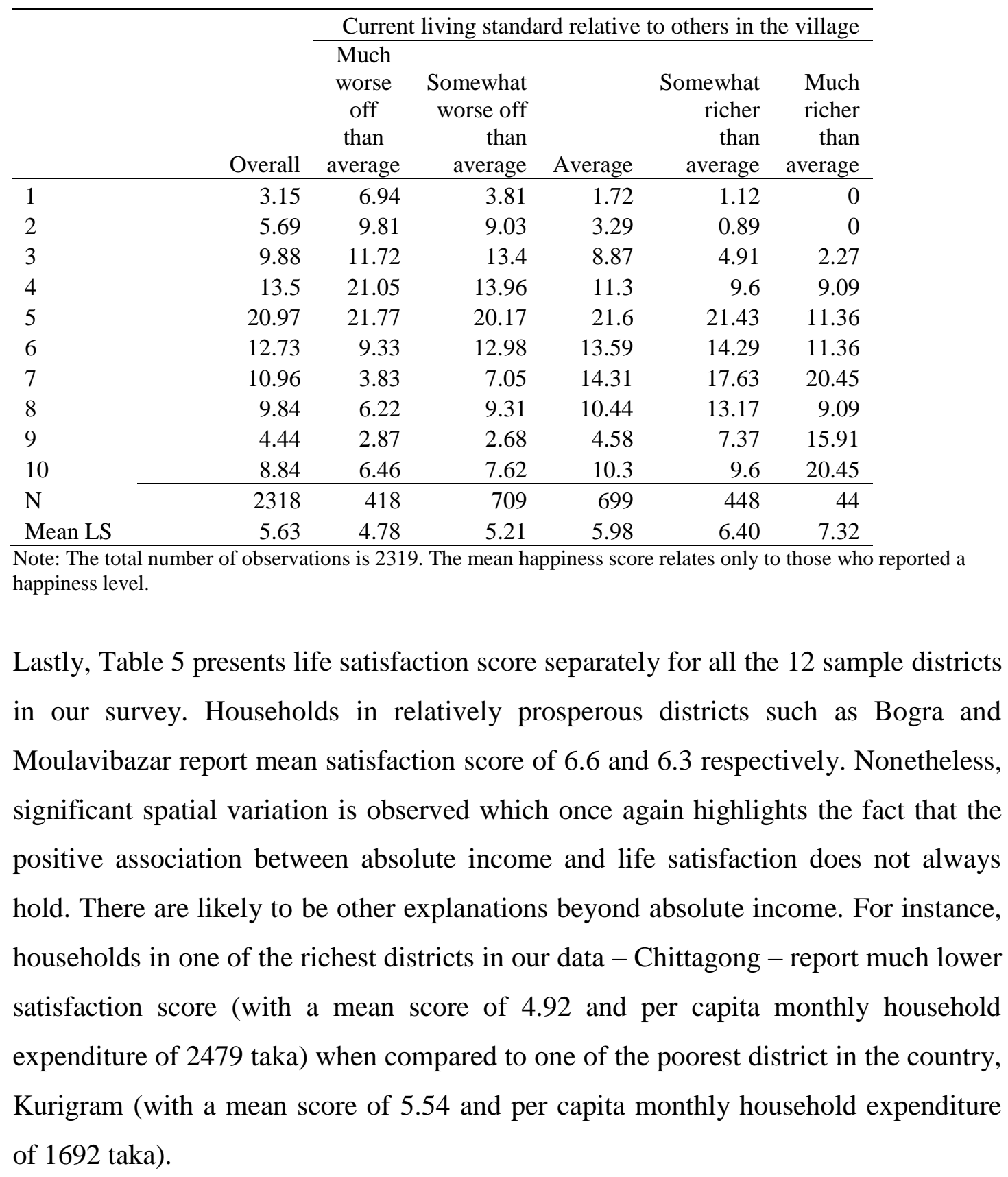


Table 5: The percentage of respondents by level of life satisfaction and by comparison of current wealth with that of other villagers

\begin{tabular}{lccc}
\hline & Mean satisfaction score & Mean per capita monthly income & N \\
\cline { 2 - 4 } Northern-Southern districts & & & \\
BARISAL & 6.17 & 1938 & 192 \\
BOGRA & 6.60 & 2402 & 188 \\
JESSORE & 5.20 & 1873 & 198 \\
KURIGRAM & 5.54 & 1692 & 197 \\
Central districts & & & \\
FARIDPUR & 5.97 & 1856 & 195 \\
MYMENSINGH & 4.68 & 1736 & 195 \\
Western districts & & & \\
CHANDPUR & 6.11 & 2270 & 194 \\
CHITTAGONG & 4.92 & 2479 & 184 \\
COMILLA & 5.42 & 2347 & 193 \\
LAKSHMIPUR & 4.42 & 2181 & 195 \\
MOULAVIBAZAR & 6.31 & 2478 & 196 \\
SYLHET & 6.26 & 2026 & 191 \\
Total & 5.63 & 2103 & 2318 \\
\hline
\end{tabular}

Note: Per capita figures are in taka and adjusted for adult equivalence.

In sum, the discussion presented in this section suggests that non-income correlates of well-being and relative economic position are likely to be relevant even for households in a low income country like Bangladesh. In the next section, we explore this formally by examining the link between well-being and a variety of social and institutional correlates.

\section{Methodology}

As pointed out earlier, subjective wellbeing in our data is measured by using responses to self-reported life-satisfaction on a 10 point likert scale -- the higher the number the more satisfied an individual is. Therefore, our basic method is to estimate subjective well-being (that is, happiness) functions of the form

$W_{i}^{*}=a_{o}+\ln (y i) b_{0}+X_{i} c_{o}+u_{i}$

where $\ln (\mathrm{yi})$ is the log of level of income of the respondent's household, $X_{i}$ a vector of personal and socioeconomic variables and $W_{i}^{*}$ is a latent variable and what is observed is different categories of an ordered categorical variable. Eq. (1) is estimated 
by an ordered probit estimator since there is an inherent ordering in our measure of well-being, $W_{i}$.

Estimate of the correlation between absolute income and life satisfaction obtained from equation (1) can proxy for factors such as income relative to others and income relative to that in the past, or for other variables correlated with income such as economic shocks, poor health status and community characteristics. Therefore, we additionally report estimate of the following wellbeing equation:

$W_{i}^{*}=a_{1}+\ln (y i) b_{1}+X_{i} c_{1}+Y_{i} \mathrm{~d}_{1}+Z_{i} \mathrm{~g}_{1}+e_{i}$

where $X_{i}$ is a vector of socioeconomic variables, $Y_{i}$ a vector of relative economic position and $Z_{i}$ a vector of community characteristics. The vector $X_{i}$ comprises of variables such as age, age-squared, marital status, educational attainment, health status of the respondent and household-specific shocks experienced during the last 12 month.

Income is often viewed as an endogenous variable in the wellbeing equation. Genetic personality differences (e.g. optimism and extrovert personality) and health status predict level of life satisfaction and these also remain correlated with income. Estimated effect of absolute income therefore can be contaminated by these unmeasured personality differences (Helliwell and Huang, 2005) and circumstance factors. In our dataset, we have information on exposure to adverse economic shocks and health status of the respondent. Therefore, both factors are controlled for in the regression analysis. However, we do not have information on personality traits of individuals because of which income variable may still remain endogenous. In the absence of information on personality attributes, one practice in the literature is to instrument household income using information on household expenditure (e.g. see Kingdon and Knight, 2007). Instead, we use data on adult-equivalent per capita monthly (food as well as non-food) expenditure as a direct proxy for household income. Compared to income, this measure is arguably somewhat exogenous.

The main hypothesis we test using equation (2) relates to the importance of absolute income. We expect more income to improve happiness but only until basic needs are 
met. For individuals with sufficient income to be able to avoid hunger, preventable disease, and absolute poverty, additional gains in income should not matter for happiness.

Nonetheless, the correlation between life satisfaction and income may be the outcome of a "focusing illusion" -- respondents may compare their incomes with some standard set by their own previous incomes or by the economic status of others in the community (Deaton, 2008). It is therefore possible that, over the long run, increases in income will generate no increase in life satisfaction. This result is consistent with the micro-level evidence from the German Socioeconomic Panel by Di Tella, HaiskenDe New, and MacCulloch (2007) who regress life satisfaction on income and on several lags of income and find that life satisfaction adapts completely to income within four years. In this work, income growth provides only a temporary boost to life satisfaction. If so, controlling for relative living standard (compared to others in the community as well as compared to one's past economic status), there should be no correlation between levels of life satisfaction across individuals at different levels of income.

As explained in the previous sections, we asked two questions to ascertain relative income of the household. One question asked respondents to indicate on a scale of 1-5 whether their current wealth is better or worse than what it used to be 5 years ago. The other question asks respondents to indicate on a scale of 1-5 whether their current wealth is higher or lower compared to others in the village. We use subjective responses to both questions as measures of relative income ${ }^{12}$.

To assess the influence of inequality, we experiment with two measures: land inequality and human capital (proxied by years of schooling completed) inequality. Inequality may reduce happiness because individuals prefer equal society (i.e. inequality belongs in their well-being function). In addition, in the absence of social

\footnotetext{
${ }^{12}$ An alternative approach involves using mean income of the village in the wellbeing function as a measure of relative income of "others". However, we do not have information on income of all the households in our sample villages - data is limited to 25 households per village. Since this does not yield an estimate of relative income that is representative at the village level, we discard this alternative approach in our analysis.
} 
mobility ${ }^{13}$, the poor will view current poverty as a predictor of future poverty and hence remain dissatisfied in an unequal village ${ }^{14}$. Lastly, inequality may reduce aggregate welfare because of diminishing marginal welfare of consumption. Therefore, inequality should matter more for the poor rather than the non-poor.

As pointed out earlier, Bangladesh has a poor system of governance. Individuals in their daily lives often have to deal with corrupt civil servants and even use bribe to access public health facilities, legal services and secure protection from the police. Fortunately, our survey included a question which asked respondents to rate their confidence in police on a scale of 1-5. We use this data as a proxy for the level of institutional trust. However, lack of institutional trust can also be a proxy for lack of general (i.e. social) trust in rural areas. Therefore, we also include a control for level of general trust in our 96 sample villages ${ }^{15}$. This is based on individual level response to the question (on a scale of 0-10): "Generally speaking, would you say that most people can be trusted or that you cannot be too careful in dealing with people?".

Dissatisfied individuals in rural Bangladesh may live in under-provided areas which lack access to basic infrastructure such as roads and health care facilities. Therefore, we include an index of village development that ranges between 0 (no facilities) and 7 (having a police station, post office, health care centre, pucca road, telephone line, electricity and satellite dish).

In sum, we intend to test the following hypotheses: (a) Is the effect of absolute dominated by that of relative income? (b) How does relative income effect varies across income levels? (c) Is income effect dominated by concerns for attaining basic needs of the households? (d) Does inequality lower well-being? (e) Do institutions matter for well-being?

\footnotetext{
${ }^{13}$ Studies on social mobility are limited for Bangladesh. One exception is Asadullah (2011) which uses household wealth data for generations of the same family from Matlab thana and report low intergenerational mobility.

${ }^{14}$ Given low level of income and high social mobility, inequality and/or income of the peers can lead to a positive effect on subjective well-being (see Jiang et al (2009) for a similar finding for China - urban residents become happier when their incomes increase within their group's income distribution.).

${ }^{15}$ This variable is constructed using data from village census.
} 


\section{Main results}

Main results are reported in Table 6. Column 1 presents estimates of well-being function obtained from a parsimonious model where we only control for the respondent's age, age-squared, gender, marital status, educational attainment and household per capita income. The estimates presented in the following column include control for wealth relative to that five years ago and others in the village. Column 3 expands the well-being function by including measures of health status, shocks and institutional trust. Models reported in columns 4 and 5 respectively add control for inequality and social trust.

Table 6: Ordered probit estimates of determinants of well-being

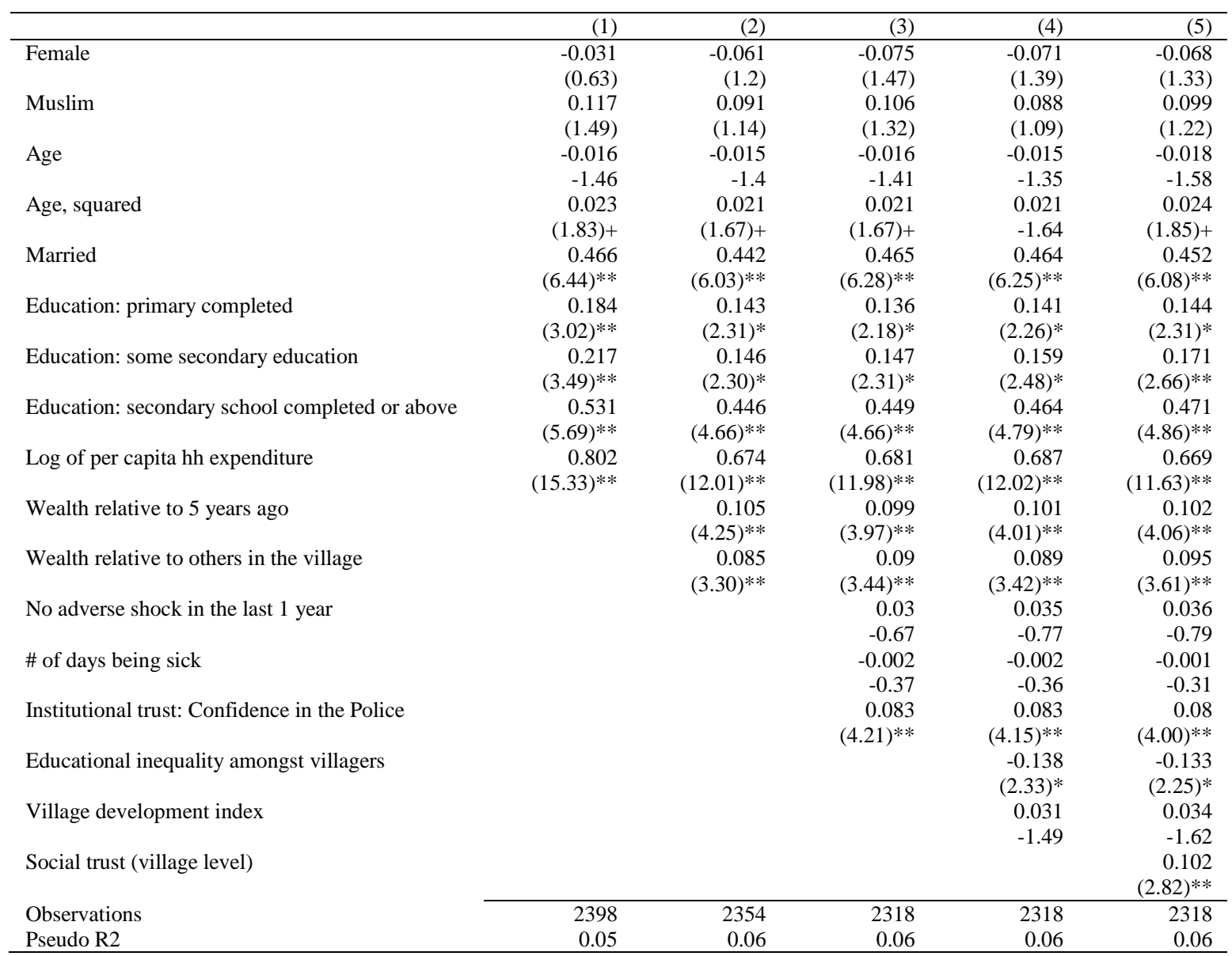

Note: (1) All regressions include a full set of district dummies. (2) In all equations robust standard errors are estimated assuming errors to be clustered by village.

Age effects are estimated by a quadratic form in age; in all cases there is a general Ushaped patter which is consistent with the international literature (e.g. see Halliwell, 2006). Consistent with other developing country studies, marital status also influences 
happiness. This is attributed to the fact that compared with unmarried people, married people can enjoy a family life and thus they have higher happiness scores. Happiness is also higher for the more educated. Our regression includes 3 education dummy variables - primary, some secondary and secondary completed and above as controls for basic needs ${ }^{16}$. Educational attainment significantly increases happiness scores in a non-linear manner with the effect being increasingly larger for more educated individuals. However, religion and gender has no significant effect in our data. Once again, all these findings are consistent with the existing literature (see Blanchflower, 2008).

The main correlate of interest however is per capita consumption, a proxy for household income. Column 1 in Table 6 confirms that higher incomes represent a gain to the satisfaction of individuals. In looking at the correlation between income and life satisfaction, it is of course possible that income is standing in for something else, such as relative income and income relative to past income, or for other variables correlated with income such as economic shock and poor health status. Therefore, it is unsurprising that the size of the income coefficient is significantly reduced when relative economic position is controlled for in our model (i.e. when moving from model 1 to model 5). To put this differently, the non-economic variables in happiness equations enter with large (but not bigger) coefficients relative to that on absolute income. However, not all added variables are equally important in washing out the coefficient on household expenditure variable. The biggest drop occurs when we move from model 1 to model 2 which adds two measures of relative income. Across models 3-5, the coefficient on household expenditure remains stable. All these 3 models include a measure of health status and exposure to economic shocks. However, "number of days sick" was never significant. This finding could be owing to the fact that people adapt to health shocks ${ }^{17}$.

There are three other interesting findings that follow from Table 6. First, institutional trust, defined in terms of confidence in police, significantly and positively enters the happiness function (see models 3-5). This is consistent with the cross country

\footnotetext{
${ }^{16}$ We also experimented with few additional measures of basic needs constructed using information on conditions of the house (for a similar approach, see Kingdon and Knight, 2006). However, these variables did not turn out to be insignificant and hence discarded from the analysis.

${ }^{17}$ We thank an anonymous referee of this journal for pointing out this issue.
} 
literature (e.g. Di Tella and MacCulloch, 2006; Helliwell, 2006; Helliwell and Huang, 2008a; Helliwell and Wang, 2008b). Second, even after controlling for institutional trust, wellbeing is affected by inter-personal or social trust. This finding highlights the importance of relational goods (e.g. having someone to count on) in determining wellbeing. Third, educational inequality amongst villagers reduces well-being. Note that this finding is not driven by the fact that villages with greater inequality are characterised by poor provision of public goods and infrastructure as our models 4 and 5 already include an index capturing the availability of various facilities in the village.

Lastly, it should be kept in mind that the ordered probit model estimates a single equation over all levels of the dependent variable under the assumption of proportional odds or parallel regression (Long and Freese, 2005) ${ }^{18}$. We implemented a test of parallel regression assumption in STATA using the command-Brant- based on an ordered logit model. However, the brant test statistic could not be computed for our dataset -- all of the independent variables in the ordered model could not be retained in all of the implied binary models owing to the fact that some binary models have many independent variables and at the same time few observations in the extreme categories (of the well-being score). We also considered an alternative non-linear economic procedure, generalized ordered logit model, which does not require the assumption of parallel regression to hold (results not shown). It is reassuring that when estimated, the main variables of interest - absolute and relative income measures -remain significant predictors of well-being in almost all equations corresponding to different categories of well-being score.

\section{Interaction between absolute and relative income}

We further explore how the importance of relative income highlighted in Table 6 varies with absolute income. To be precise, we examine whether relative income affects subjective well-being differently among the poor and better-off households. To this end, households are split in two groups: the bottom $40 \%$ and top $60 \%$ expenditure

\footnotetext{
${ }^{18}$ However, we can't formally test this hypothesis in the absence of detail health data. One developing country study on well-being that directly addresses this issue is Fafchamps and Kebede (2008). They authors find no evidence in support of the idea of adaptation: people in households that had experienced disability for long periods were not happier than those in households that had experienced it only recently.
} 
quintiles. This approach is equivalent to the conventional approach of interacting the expenditure quintiles with the regressors ${ }^{19}$.

Estimates of well-being function specific to the two sub-samples are reported in Table 7. Absolute income always exerts a significant, positive influence on life satisfaction score in the parsimonious model (i.e. model 1). The results support a finding that the relationship between the household income and life satisfaction is well-correlated for both poor and better-off households. In other words, there does not seem to be a threshold level above which income has no further effect on life satisfaction. At the same time, there is some evidence of deviation -- the coefficient on absolute income for the poorer households is almost always twice that of the richer households. In other words, the satisfaction-income gradient is steepest amongst the poorer households. Interestingly enough, this finding is consistent with the international pattern of life satisfaction with respect to GDP per capita -- cross country studies report a much steeper relationship among the poor countries than among the rich (see Deaton, 2008).

\footnotetext{
${ }^{19}$ As per the nationally representative Household Income and Expenditure Survey (HIES) 2005, 40\% of the Bangladeshi households live below the poverty line. Our expenditure module is not identical to HIES 2005 and for that reason, it was not possible to calculate the HIES-based poverty line using our data. Therefore, as a rough approximation, we used the bottom two quintiles to define the poor.
} 
Table 7: Ordered probit estimates of determinants of well-being by income quintiles

\begin{tabular}{|c|c|c|c|c|c|c|c|c|}
\hline & \multicolumn{4}{|c|}{ Bottom $40 \%$} & \multicolumn{4}{|c|}{ Top 60\% } \\
\hline & (1) & $(2)$ & (3) & (4) & (1) & (2) & (3) & (4) \\
\hline Female & $(1.71)+$ & $(2.03)^{*}$ & $(2.20)^{*}$ & $(2.12)^{*}$ & -0.68 & -0.18 & -0.13 & -0.04 \\
\hline Muslim & -0.113 & -0.115 & -0.126 & -0.134 & 0.214 & 0.176 & 0.197 & 0.19 \\
\hline \multirow[t]{2}{*}{ Age } & -0.024 & -0.027 & -0.03 & -0.027 & -0.014 & -0.012 & -0.01 & -0.015 \\
\hline & -1.21 & -1.32 & -1.46 & -1.34 & -1.04 & -0.86 & -0.74 & -1.08 \\
\hline \multirow[t]{2}{*}{ Age, squared } & 0.033 & 0.034 & 0.036 & 0.035 & 0.021 & 0.018 & 0.016 & 0.021 \\
\hline & -1.4 & -1.44 & -1.53 & -1.45 & -1.38 & -1.15 & -1.05 & -1.37 \\
\hline \multirow{2}{*}{ Education: primary completed } & 0.177 & 0.107 & 0.085 & 0.112 & 0.179 & 0.157 & 0.154 & 0.167 \\
\hline & -1.62 & -0.96 & -0.76 & -0.99 & $(2.43)^{*}$ & $(2.10)^{*}$ & $(2.04)^{*}$ & $(2.21)^{*}$ \\
\hline \multirow[t]{2}{*}{ Education: some secondary education } & 0.121 & 0.049 & 0.043 & 0.074 & 0.243 & 0.18 & 0.181 & 0.212 \\
\hline & -0.96 & -0.38 & -0.34 & -0.57 & $(3.35)^{* *}$ & $(2.43)^{*}$ & $(2.44)^{*}$ & $(2.82)^{* * *}$ \\
\hline \multirow[t]{2}{*}{ Education: secondary school completed or above } & 0.814 & 0.654 & 0.666 & 0.715 & 0.547 & 0.476 & 0.478 & 0.501 \\
\hline & $(3.44)^{* *}$ & $(2.67)^{* *}$ & $(2.71)^{* *}$ & $(2.89)^{* * *}$ & $(5.27) * *$ & $(4.49) * *$ & $(4.48)^{* *}$ & $(4.65)^{* *}$ \\
\hline \multirow[t]{2}{*}{ Log of per capita hh expenditure } & 0.899 & 0.791 & 0.769 & 0.78 & 0.591 & 0.459 & 0.476 & 0.441 \\
\hline & $(5.89)^{* *}$ & $(4.98) * *$ & $(4.82) * *$ & $(4.85)^{* *}$ & $(6.50)^{* *}$ & $(4.85)^{* * *}$ & $(5.00)^{* *}$ & $(4.59)^{* *}$ \\
\hline Institutional trust: Confidence in the Police & & & $(3.04)^{* * *}$ & $\begin{array}{r}(2.79)^{* *} \\
0.049\end{array}$ & & & $\begin{aligned}(3.18)^{* * *} \\
0.03\end{aligned}$ & $\begin{array}{r}(3.20)^{* *} \\
0.027\end{array}$ \\
\hline No adverse shock in the last 1 year & & & $\begin{array}{r}0.035 \\
-0.48\end{array}$ & $\begin{array}{r}0.049 \\
-0.67\end{array}$ & & & $\begin{array}{r}0.03 \\
-0.52\end{array}$ & -0.47 \\
\hline \multirow[t]{2}{*}{ \# of days being sick } & & & 0.003 & 0.003 & & & -0.004 & -0.003 \\
\hline & & & -0.39 & -0.33 & & & -0.73 & -0.55 \\
\hline \multirow[t]{2}{*}{ Educational inequality amongst villagers } & & & & -0.157 & & & & -0.116 \\
\hline & & & & $(1.77)+$ & & & & -1.42 \\
\hline \multirow[t]{2}{*}{ Village development index } & & & & -0.018 & & & & 0.063 \\
\hline & & & & -0.51 & & & & $(2.39)^{*}$ \\
\hline \multirow[t]{2}{*}{ Social trust (village level) } & & & & 0.05 & & & & 0.138 \\
\hline & & & & -0.85 & & & & $(2.88)^{* *}$ \\
\hline Observations & 931 & 909 & 895 & 895 & 1467 & 1445 & 1423 & 1423 \\
\hline Pseudo R2 & 0.05 & 0.06 & 0.06 & 0.06 & 0.03 & 0.04 & 0.04 & 0.04 \\
\hline
\end{tabular}

Note: (1) All regressions include a full set of district dummies. (2) In all equations robust standard errors are estimated assuming errors to be clustered by village. 
The above conclusions remain unchanged even when we consider much detailed regression specifications (i.e. models 2-4) which account for other factors such as relative income, income relative to past income, economic shock, poor health status, trust (institutional as well as social) and community characteristics. The influence of income relative to past income as well as others in the village remains significant and positive for all income groups. Accounting for these additional factors reduces the coefficient on absolute income variable by $12 \%$ and $25 \%$ for poorer and better-off households respectively.

Similar non-linearity is observed with respect to the influence of institutional trust. Irrespective of the regression model used, poorer households gain more satisfaction from increased institutional trust when compared to well-off households. This result is consistent with the earlier observation that poorer households express less confidence in police compared the better-off households. It therefore also confirms the hypothesis that corruption and distrust remain as core well-being issues in rural Bangladesh.

\section{Conclusion}

This paper has revisited the debate over absolute vs. relative income as a correlate of subjective well-being by using data from rural Bangladesh. Ours is the first estimate of well-being function for Bangladesh. The estimates of the micro-determinants of well-being obtained show that relative income matters for individual well-being: individuals who report their wealth to be lower than others in the village also report less satisfaction with life. There are significant interaction effects as well - poorer individuals draw greater satisfaction from absolute income remains compared to better-off individuals. Our finding also adds to the growing body of evidence in favour of the assumption that relative consumption matters for the rich as well as for the poor. However, when compared to the effect of absolute income, these effects remain modest. Relative deprivation is not the dominant concern for an average respondent in our data, although it is for the comparatively well off.

Our results also indicate that income poverty is not the sole correlate of wellbeing. Amongst other factors, we find that institutional quality -- measured in terms of 
confidence in police -- also enters with a positive and significant coefficient in the wellbeing function. Similarly, economic equality and infrastructure development in the village increase life satisfaction of individuals.

In sum, findings reported in this paper highlight the need to study poverty using a multi-dimensional framework. Almost all the existing quantitative research on poverty in Bangladesh has focused on income based indicator of well-being (e.g. see Hossain, 2009) and have subsequently ignored the debate over relative versus absolute notion of deprivation. In addition, existing studies have also overlooked institutional correlates of poverty. Future research on poverty should therefore not only look at psychological indicators of poverty, they should also take into account the quality of local-level public institutions. The meaning of poverty based on a notion of low income should be contrasted with that based subjective perceptions of economic position. In addition, Bangladesh currently has a number of large-scale antipoverty programmes in place such as "Targeting the Ultra-poor" (TUP) and "Challenging the Frontiers of Poverty Reduction (CFPR)" initiatives. Evaluation of these schemes should look beyond income based indicators and simultaneously assess well-being using subjective indicators. Lastly, ours is a first attempt to study wellbeing in rural Bangladesh beyond one's own objective circumstances. However, we have not considered all dimensions of subjective wellbeing (e.g. satisfaction with health, education and work, adequacy of consumption), the specific reference group that an individual may chose for social comparison purposes and psychological correlates of poverty. These issues are relevant for understanding the determinants of well-being even in a low income country context (for a discussion, see Anand and Lea, 2011). Future investigation into subjective well-being data should take into account these issues to identify social aspects of poverty dynamics in Bangladesh. 


\section{Reference}

Asadullah, M Niaz (2011), "Intergenerational wealth mobility in rural Bangladesh," Institute for the Study of Labor Discussion Paper number 5914.

Ahmed and Shams (1994), "Demand Elasticities in Rural Bangladesh: An Application of the AIDS Model," The Bangladesh Development Studies, Vol. 22(1), pp. 1-25.

Alesina, A, R., Di Tella and R.J. MacCulloch (2004), "Inequality and happiness: are Europeans and Americans different?", Journal of Public Economics, Vol. 88, pp. 2009-2042.

Anand, Paul and Stephen Lea (2011) "The psychology and behavioural economics of poverty”, Journal of Economic Psychology, pp. 284-293.

Blanchflower, David G. (2008). International Evidence on Well-being. IZA DP No. 3354. Institute for the Study of Labor, Bonn.

Blanchflower, D.G., and A.J. Oswald (2008), 'Hypertension and happiness across nation', Journal of Health Economics, vol. 27(2), Pages 218-233.

Beegle, Kathleen \& Himelein, Kristen \& Ravallion, Martin, 2009. "Frame-ofreference bias in subjective welfare regressions," Policy Research Working Paper Series 4904, The World Bank.

Carlsson, Fredrik, Gautam Gupta and Olof Johansson-Stenman (2009) "Keeping up with the Vaishyas? Caste and relative standing in India," Oxford Economic Papers, vol. 61(1), pages 52-73.

Clark, A.E., and A.J. Oswald (1994) "Unhappiness and unemployment", The Economic Journal, 104, pp. 648-659.

Clark, Andrew E., (2003) "Unemployment as a Social Norm: Psychological Evidence from Panel Data," Journal of Labor Economics, University of Chicago Press, vol. 21(2), pages 289-322, April.

Clark, Andrew E., Paul Frijters \& Michael A. Shields (2008) "Relative Income, Happiness, and Utility: An Explanation for the Easterlin Paradox and Other Puzzles," Journal of Economic Literature, vol. 46(1), pages 95-144, March.

Clark, Andrew E., Nicolai Kristensen and Niels Westergård-Nielsen (2009) "Economic Satisfaction and Income Rank in Small Neighbourhoods," Journal of the European Economic Association, vol. 7(2-3), pages 519-527, 04-05.

Camfield, L, Choudhury, K, and Devine, J (2009), "Relationships, Happiness and Well-being: Insights from Bangladesh", Journal of Happiness Studies, Vol 10(1), pp 71-91. 
Chaudhury, N. \& Jeffrey Hammer \& Michael Kremer \& Karthik Muralidharan \& F. Halsey Rogers (2006) "Missing in Action: Teacher and Health Worker Absence in Developing Countries," Journal of Economic Perspectives, vol. 20(1), pages 91-116, Winter.

Chaudhury, N. and J.S. Hammer (2003), "Ghost Doctors: Absenteeism in Bangladesh Health Facilities," Policy Research Working Paper 3065, World Bank, Washington, D.C.

Deaton, Angus (2008) "Income, Health, and Well-Being around the World: Evidence from the Gallup World Poll," Journal of Economic Perspectives, vol. 22(2), pages 5372.

Di Tella, R. and R.J. MacCulloch (2006), 'Some uses of happiness data in economics', Journal of Economic Perspectives, 20(1), Winter, pp. 25-46.

Easterlin, R. (1974), 'Does economic growth improve the human lot? Some empirical evidence', in David, P.A., Reder, M.W. (Eds.), Nations and households in economic growth, essays in honor of Moses Abramowitz, Academic Press, New York.

Fafchamps, M. and Bereket Kebede (2008) "Subjective well-being, disability and adaptation: A case study from rural Ethiopia", in Adaptation and Well-Being, David Clark (ed.), Cambridge University Press.

Fafchamps, Marcel and Forhad Shilpi, F., 2009. "Isolation and Subjective Welfare: Evidence from South Asia," Economic Development and Cultural Change 57(4): 64183.

Graham, Carol (2005). "Insights on development from the economics of happiness", World Bank Research Observer, 20, pp. 201-231.

Graham, Carol and Pettinato, Stefano (2002). 'Frustrated achievers: winners, losers and subjective well-being in new market economies' Journal of Development Studies, 384, April: 100-40.

Guillen-Royo, Monica (2011) "Reference group consumption and the subjective wellbeing of the poor in Peru", Journal of Economic Psychology, pp. 259-272.

Helliwell, John F. (2004) Well-Being and Social Capital: Does Suicide Pose a Puzzle? NBER Working Paper no. W10896.

Helliwell, J. (2003) "How's Life? Combining Individual and National Variables to Explain Subjective Well-Being", Economic Modelling 20(2): 331-60.

Helliwell, John F. and R.D. Putnam (2004) 'The social context of well-being' Phil Trans R. Soc Lon. B vol. 359, pp. 1435-46. To be reprinted in F.A. Huppert, B. Kaverne and N. Baylis, eds., The Science of Well-Being. London: Oxford University Press.

Helliwell, J. (2006) "Well-Being, Social Capital and Public Policy: What's New?" Economic Journal, Vol. 116, pp. C34-45. 
Helliwell, J. and Huang, Haifang (2008a) "How's Your Government? International Evidence Linking Good Government and Well-Being”, British Journal of Political Science, Vol. 38: 595-619.

Helliwell, J. and Huang, Haifang (2008b) "International Differences in the Determinants of Life Satisfaction" John F. Helliwell and Haifang Huang and Anthony Harris. Forthcoming in Tridip Ray, E. Somanathan, and Bhaskar Dutta (eds.) "New and Enduring Themes in Development Economics", World Scientific.

Helliwell, John F. and Huang, Haifang (2009) "How's the Job? Well-Being and Social Capital in the Workplace," Industrial \& Labor Relations Review, Vol. 63(2), pp

Helliwell, John F. and Shun Wang (2010) "Trust and Well-being", NBER Working Paper No. 15911.

Hossain, Mahabub (2009) "Dynamics of Poverty in Rural Bangladesh, 1988-2007: An Analysis of Household Level Panel Data", Paper presented in the Conference on "Employment, Growth and Poverty Reduction in Developing Countries" organized by the Political Economy Research Institute, University of Massachusetts, Amherst in honor of Professor Azizur Rahman Khan, March 27-28, 2009.

Jiang, Shiqing \& Ming Lu \& Hiroshi Sato (2009) "Happiness in the Dual Society of Urban China: Hukou Identity, Horizontal Inequality and Heterogeneous," Global COE Hi-Stat Discussion Paper Series gd08-020, Institute of Economic Research, Hitotsubashi University.

Kahneman, D. and A.B. Krueger (2006), 'Developments in the measurement of subjective wellbeing', Journal of Economic Perspectives, 20(1), pp. 3-24.

Kingdon, G. and J. Knight (2007) 'Community, comparisons and subjective wellbeing in a divided society', Journal of Economic Behavior and Organization, 64, pp. 69-90.

Kingdon, G. and J. Knight (2006) "Subjective well-being poverty vs. Income poverty and capabilities poverty?," The Journal of Development Studies, vol. 42(7), pages 1199-1224.

Knight, John, Song, Lina and Gunatilaka, Ramani (2009) "Subjective well-being and its determinants in rural China," China Economic Review, vol. 20(4), pages 635-649, December.

Knight, John and Gunatilaka, Ramani (2010) "Great Expectations? The Subjective Well-being of Rural-Urban Migrants in China," World Development, vol. 38(1), pages 113-124.

Kohler, Hans Peter, Jere Behrman and Axel Skytthe (2005) "Partner + Children = Happiness? An Assessment of the Effect of Fertility and Partnerships on Subjective Well-Being." Population and Development Review. 31:3, pp. 407-45. 
Luttmer, E. (2005) "Neighbors as negatives; relative earnings and well-being", Quarterly Journal of Economics, August, 120(3), pp. 963-1002.

Long, J. Scott and Jeremy Freese, 2005, Regression Models for Categorical Outcomes Using Stata. Second Edition. College Station, TX: Stata Press.

Mahmud, Wahid, Sadiq Ahmed and Sandeep Mahajan (2008), Economic Reforms, Growth and Governance: The Political Economy Aspects of Bangladesh's Development Surprise, Working Paper No. 22, World Bank on behalf of the Commission on Growth and Development, Washington, D.C.

McGregor, J. Allister, Andrew McKay and Jackeline Velazco (2007) "Needs and resources in the investigation of well-being in developing countries: illustrative evidence from Bangladesh and Peru," Journal of Economic Methodology, vol. 14(1), pages $107-131$.

Nabi, R., Datta, D., Chakrabarty, S., Begum, M., and Chaudhury, N. (1999) "Consultation with the poor: Participatory Poverty Assessment in Bangladesh". The World Bank.

Oswald, A. J. (1997) 'Happiness and economic performance', Economic Journal, 107, pp. 1815-1831.

Ravallion, Martin and Lokshin, Michael (2010) "Who cares about relative deprivation?," Journal of Economic Behavior and Organization, vol. 73(2), pages 171-185.

Sen, Binayak and Hulme, David (2004) Chronic Poverty in Bangladesh: Tales of Ascent, Descent, Marginality and Persistence, The State of the Poorest 2004/2005. 